\title{
تشخيص معوقات تطبيق ادارة الجودة الشاملة في جامعة نوروز/دهوك دراسة استطلاعية لاراء اعضاء الهيئة الثدريسية
}

\author{
د. محفوظ حمدون عبد الصواف \\ استاذ \\ كلية الادارة والاقتصاد، قسم الاقتصاد، جامعة نوروز \\ اقليم كوردستان العراق
}

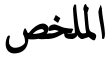

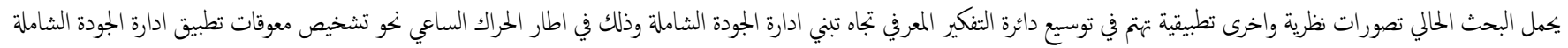

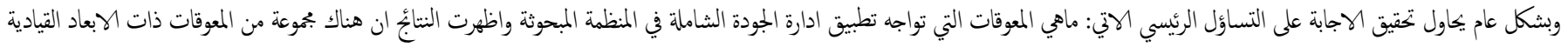

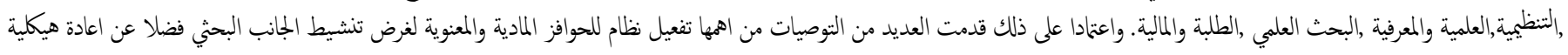

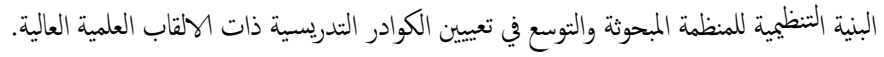

1. المقدمة

الى ان تطبيق ادارة الجودة الشاملة يحتاج الى قيادة ادارية فاعلة، الامر الذي يتطلب من المسؤولين في ادارة الجامعات العمل على معرفة المعوقات التي تواجه تطبيقها فضلا عن خلق بيئة اكاديمة تتوفر فيها قاعدة بيانات شاملة تؤشر من خلالها المشاكل والمعوقات التي يمكن ان تواجه التطبيق لذا قامت هذه الدراسة بالتزكيز على معرفة وتشخيص المعوقات التي تواجه الجامعات الههلية في تطبيق ادارة الجودة الشاملة وقد تم اختيار جامعة نوروز كمالة دراسية لقياس مدى توافر بمحوعة المعوقات والتي في ضويها يكن من اعداد توصيات تساعد ادارة الجامعة في التغلب عليها . جامعة نوروز احدى الجامعات الهملية في اقليم كوردستان والتي تأسست عام 2004, ومنذ تأسيسها تم ربط مخرجاتها بالتخصصات التي تخدم سوق العمل مثل تخصصات الادارة والاقتصاد,اللغات,هندسة الحاسبات,علوم الحاسبات,الهندسة المعحارية. وقد وابحت جامعة نوروز كغيرها من الجامعات الاهلية النقد الشديد بعد صدور تتييم عام (2015) الذي بين الاداء المثواضع للجامعات الاهلية في اقليلم كردستان عندها ادركت انها تعمل بعيدا عن انظمة الجودة والاعتماد الكادييي للذا بدأت الجامعة تعيد النظر في خططها ونتائج اعمالها وقوق فضلت العمل وفقا لمعايير الجودة والاعتماد الكادييي

$$
\text { حتى تخرج من الاجتهادات والعمل المرتجل . }
$$

بات من الواضح أن التوجه نحو تحقيق جودة التعليم الجامعي أمرال لا خيار فيه ولايكن تجاوزه, فتحقيق اعلى مستوى من الجودة يمثل استجابة ضرورية لموابجة العديد من المتغبرات التي تواجتها الجامعات الاهلية في اقليم كردستان/العراق . وتعتبر محاولة تحقيق جودة التعليم الجامعي وتطبيق نظم ادارة الجودة الشاملة فيه احدى المداخل التي تمكنها من القيام بوظائنها التعلمية والبحثية والمجتمية بشكل مستمرتحق لها القدرة في دفع مسيرة التعليم وانغكاسته علي تنمية الموارد البشرية. فالجودة هي السلاح الفعال الذي يكن من خلاله تحقيق اهداف التعليم الجامعي . ان احداث طفرة نوعية في جودة التعليم الجامعي الاهلي تتطلب تبني انظمة فاعلة وكؤة للجودة,وقادرة على تلبية متطلبات الجمتمع والمنافسة في سوق العمل . هذه الانظمة تتجدد في ظلها معايير الاداء ، وتقديم أليات واساليب عمل قادرة على معالجة المشكلات والتحسين المستمر للعملية التعليمة .وفي هذا السياق لابد من الاشارة

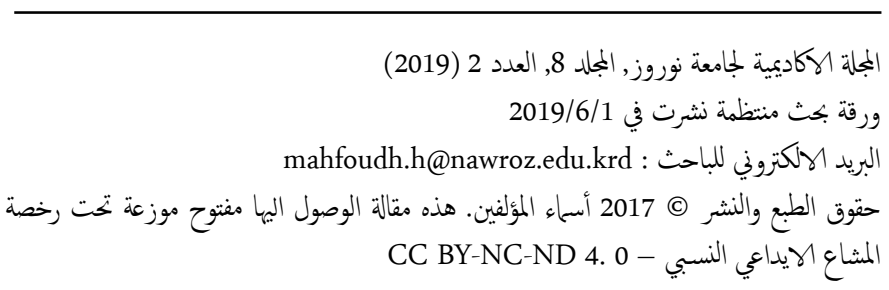


وتعتبر هذه الدراسة رافدا من روافد التغذية العكسية للجامعات الاهلية في اقليم 3.1.2 اهداف البحث

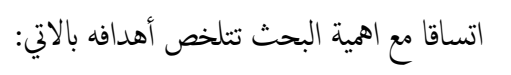

تحديد المعوقات التي تواجه الجامعة المبحوثة في عدم تطبيق ادارة الجودة الشاملة. مدى ادراك اعضاء الهيئة التدرسية في الجامعة المبحوثة بفلسفة ادارة الجودة

الشاملة.

عرض وبجات نظر اعضاء الهيئة الندريسية في الجامعة المبحوثة بشأن تطبيق

$$
\text { ادارة الجودة الثاملة. }
$$

تقديم جموعة من المقترحات للنهوض بواقع العملية التعلميمة في الجامعة المبحوثة.

\subsection{2 منهج البحث}

اعتمد الباحث المنهج الوصفي التحليلي في تحليل البيانات التي تم جمعهاوكن هذا المنهج يركزعلى استطلاع اراء المبحوثين وتوجهانهم. تم استخدام المنجج الوصفي لوصف واقع المتغيرات المدروسة راما المنهج التحليلي تم استخدامه في تحليل ننائج المعالجات الاحصائية لمتغيرات البحث واستخلاص الاستناجات التي على اساسها تم عرض

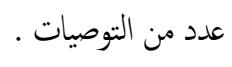

\subsection{2 فرضية البحث}

توجد بموعة من المعوقات التي تحول دون تطبيق ادارة الجودة الشاملة في الجامعة البمحوثة من وبحة نظر اعضاء الهيئة التدريسية.

\subsection{2 جمتم البحث}

اشتمل مجتمع البحث على كافة التدريسيين في الكليات التابعة لجامعة نوروز وهي كلية الادارة والاقتصاد, كلية القانونكلية اللغات,كلية الحاسوب,كلية الهندسة تم توزيع (70) استمارة استبانة على هؤلاء التدريسيين وقد تم استرجاع (57)استمارة استبانة كانت جميعها صالحة للتحليل ومثلت نسبة الاستجابة (81,4\%).

\subsection{2}

الحدود الزمنية -- والتي انحرت في المدة ما بين 9-19-2019 -2019-4 الما

$$
\text { الحدود المكانية-- حيث اختيرت جامعة نوروز كيدان لاجراء البحث . }
$$

الحدود البشرية-- شملت كافة اعضاء الهيئة الندريسية في الجامعة المبحوثة .
كردستان بشكل عام وجامعة نوروز بشكل خاص، نأمل ان توظف ننائجها في اصلاح بعض الخللل وتستعجل بعض الامور في مجال اعادة بناء النعليم العالي الاهلي على وفق معايير معرفية.

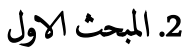

\section{2 منهجية البحث}

\subsection{2 مشكلة البحث}

تواجه جامعة نوروز كغيرها من الجامعات الههلية في اقليم كردستان النقد الشديد يعد صدور تقييم اداء الجامعات وتصنيفها الصادر عن وزارة التعليم العالي والبحث العلمي في اقليم كوردستان لعام (2015) , وكان اهم ما ورد فيه ان الجامعات بشكل عام تعمل بعيدا عن انظمة الجودة العالمية والاعتماد الكاديمي. وقد يكون السبب الرئيس هو تركيز الاهتمام في المرحلة السابقة كان منصبا على اعداد البنية التحتية من ابنية ومختبرات ذات جودة عالية على حساب تطوير البرامج الكاديية واعداد الاطر التدريسية والبحث العلمي . والسؤال الذي يطرح نقسه في هذا المجال هو ما مدى امكانية الجامعات الاهلية على الموابحة لاحداث يقظة تدفع باتجاهت جاوز الواقع الحالي والاتقال الى حالة جديدة لتغير بناء ذاتها وفقا للمعايير الدولية المعترف بها فضلا عن الاستفادة من تطبيق ادارة الجودة الشاملة بشكل عام يككن التعبيرعن مشكلة البحث في التساؤلات التالية: 1-ماهي المعوقات التي تحد من تطبيق ادارة الجودة الشاملة. 2- ما مدى ادراك التدريسيين العاملين في الجامعة المبحوثة بفلسفة ادارة الجودة الشاملة.

\subsection{2 اهية البحث}

ثكمن اهية البحث في محاولته للتصدي لموضوع اصبح يشغل اهتمام الكثير من ادارات الجامعات الاهلية وهو ادارة الجودة الشاملة وامكانية تطبيقها ,الامر الذي دفع الباحثين المى البحث والتقصي عن المعوقات التي تواجه عملية التطبيق وتقديم المقترحات الازمة التهيئة البنية التحتية سواء على المستوى القيادي,التنظيمي رالتعليمي والمعرفي ,البحث العلمي ,خدمة الجمتعرالتمويل والطلبة بما يعزز قدرة الجامعة على تجاوز الواقع الحلالي والتنقال الى حالة جديدة لتعيد بناء ذاتها وفقا للمعايير الدولية المعترف بها. 
النهائي بل الوصول الم اسعاده ، وان المطلوب هو ليس فقط ضان جودة المنتج ،بل

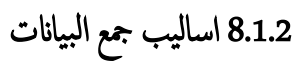
المطلوب ضان جودة المنظمة ، لان جودة المنظمة هو ضان لجودة مخرجاتها وتحسينها

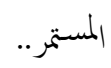

الجودة في التعليم كما اشار اليها (ابوعودة, 42004) تمثل استراتيجبات تعبر عن رؤى مخطط لها تشمل أنشطة محددة وقابالة للتطبيق بهدف الوصول المى افضل منتج تربوي وتعليمي مككن ولابد أن تقدم تلك الرؤى والاستراتيجيات على قواعد سلوكية ترسم مراحل التطبيق ، أما سكر ،2006 ، 241 ) فيذهب الى ابعد من ذلك ويشير الى ان مفهوم الجودة يتعدى جودة المنتج نفسه ليشمل العديد من الجوانب المختلفة في المؤسسة التعليمة فهو يشمل طريقة الاداء وجودة المعلومات وجودة العمليات وجودة امكاك العمل وجودة الاعال وجودة الاهداف وجودة البرامج التعليمة وجودة كل شى داخل المؤسسة التعليمة. من جانب أخر يشير (الجسر،2004،4) الى ان جودة التعليم العالي على انها مقدرة جموع خصائص ومميزات المنتج التعليمي على تلبية متطلبات الطالب وسوق العمل والجمتع وكافة الجهات الداخلية والخارجية المستفيدة .هذا المفهوم ينسجم

مع المفهوم الذي اوردته منظمة اليونسكو العالمية في مؤتمرها المنعقد في باريس عام 1998 والذي حدد مفهوم الجودة في النعليم على أنه مفهوم متعدد الابعاد ، وينبني أن يشمل جميع وظائف التعليم وانشطته مثل المناجج الدراسية، البرامج التعلمية ، الطلبة، المستلزمات المادية، خدمة المجتع، التعليم الذاتي الداخلي، فضلا عن تحديد معايير للجودة

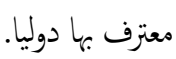

\subsection{3 مفهوم ادارة الجودة الشاملة في التعليم العالي}

على الرغ من حداثة الاهتمام بادارة الجودة الشاملة في التعليم العالي الا أن الكثير من الباحثين يشير المى اهية ادارة الجودة الشاملة في التعليم العالي وفي ضوء ذلك ادركت

الجامعات انها لم تتمكن من ضان النجاح في عالم تسوده المنافسة الشديدة دون ان تتواكب مع المعطيات الجديدة التي تفرض عليها التحول نحو مدخل جديد يكفل لها مستوى متميز من التعليم الجامعي وهذا لايتحقق الا عبر مدخل ادارة الجودة الشاملة وتعتبر جامعة ولاية أوريجون من أبرز حالات التطبيق في الولايات المتحدة الامريكية التي استطاعت ان تتبنى برنامجا شاملا للجودة على مدى خمس سنوات شمل كل فرد

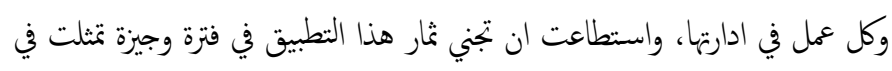




\subsection{3 مثطلبات التحول من المنهج الثقليدي المى منهج ادارة الجودة الشاملة} لكي تكمل الصورة إمام المؤسسة الأكاديية التي تزغب في تبني المنهج الجديد أو التحول من المنهج التقليدي إلى منهج إدارة الجودة الشاملة لابد أن تتبنى طرقا تتخذها كدليل استراتيجي يتلاءم مع ظروفها المادية والبشرية لكي تحقق التغير والتطوير الذي يتناسب مع أهدافها , في هذا السياق حدد (الشبتري, 2000, 112) شروطاً خمسة - استقاها

من رواد الجودة والمفكرين أمثال (Deming Crosby, Juran) وكما يأتي: تعليم الإدارة الالتزام: قبل تطبيق إدارة الجودة الشاملة لابد أن تخضع الإدارة العليا

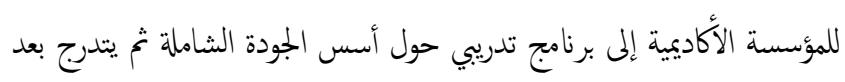

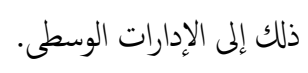

تعليم وإلزام أعضاء هيئة الثدريس والموظفين: من الضروري لنجاح تطبيق إدارة الجودة الشاملة تدريب, وتعليم أعضاء الهيئة الندريسية والموظفين على أسس إدارة الجودة الشاملة, ووسائلها, وأساليها, وكيفية تحسينها, وما يحتاجون إليه لتطبيقها, لأن ذلك يؤدي إلى التزامم بالنموذج الجديد. ترسيخ الثقة عندما تتواجد الثقة في

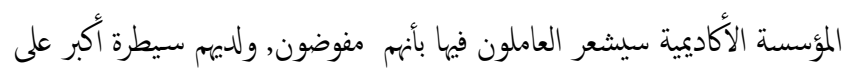
وظائنهم, مما يجعل وظائنهم أكثر فعالية إذن الثقة والتفويض كمة للإدارة التشاركة,

$$
\text { لأنها يشتركان مباثرة في تطوير محارة القيادة الذانية. }
$$

غرس الاعتزاز في العمل المهني: تتم من خلال الاعتراف بآراء الآخرين لان ذلك سيشجع العاملين من أعضاء هيئة التدريس, والموظفين على توسيع أفاقهم وتطوير إبداعهم كما يوحي بأن الثقة موجودة حتى ولو حدثت الأخطاء. تغيير ثثافة المنظمة: يمكن تغيير الثقافة التنظيمية في الجامعة أو المؤسسة التعليمية

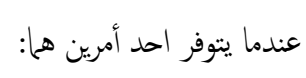

O ع ع مندما تكون المؤسسة على وشك الإغلاق.

$$
\text { O بعندما يكون هناك جهد جاعي لتغيير مسارها. }
$$

في ضوء ما جاء أعلاه يتطلب من القائد محاولة فهم كيفية نشوء الثقافة الحالية ثم بعد ذلك يركز عن طريق الأظمة لتحسين الجودة الشاملة لترسيخ الثقة / وتشجيع التفويض

$$
\text { والاعتزاز بالعمل حتى لا يتعرض جهده إلى الشامل. }
$$

أما (العلوي، 1998, 32) فقد أشار إلى بمموعة من الشروط الواجب توفرها لتطبيق
توفير الوقت، تنمية قيم العمل الجماعي، محارات حل المشكلة، تزايد الاحساس بالرضا عن العمل لدى العاملين ، اشباع رغبات الزبائن وتحقيق توقعاتهم(عشيبة، 2000، 550). حاول الغامدي تأطير مفهوم ادارة الجودة الشاملة في التعليم من خلال ثلاث عناصر اساسية أولها الفلسفة التي تستند اليها وهو التزكيز على ما يكتسبه الطالب من معارف ومهارات وقيم اخلاقية وجالية تعمل على تنميته ذاتيا أما ثانيا فهو الهدف التي تسعى المنظمة التعلمية للحصول عليه من خلال الخدمة المقدمة بأعلى مستوى مككن من الجودة وبما يتطابق مع المعايير الدولية كالآيزو وجوائز الجودة العالمية أما العنصر الاخير فهو العملية المرتبطة بالتغذية العكسية من جانب المستفيدين واصحاب المصاح لتحديد مستوى الجودة الواجب تقديها بما يتلائم مع ارضاء الزبون الى اقصى ما يمكن (الغامدي، 2006، 445).

\subsection{3 المتطلبات التي يجب توفرها لبرنامج إدارة الجودة الشاملة في الجامعات}

عند البدء بتطبيق برنامج الجودة الشاملة في مؤسسات التعليم العالي (الجامعات) ينبني توافر مجموعة من المتطلبات المتمثلة ب:( Seymour,1992)(الغامدي،2006،447) تحديد الرسالة العامة للجامعة ويفضل أن تكون مكتوبة وواضحة ليسهل تداولها ومراجعتها بين الحين والآخر, على آن يسبق ذلك وجود رؤية عامة تحدد مسار الجامعة في المستقبل ولتفعيل كل من الرؤية والرسالة لابد أن يكون الهدف العام للجامعة هو ( الالتزام بالتميز ) في كل نشاط من أنشطة الأداء الأكاديي و الإداري (تطوير العملية التعليمية، تطوير البحث العلمي، تطوير خدمة الجمتع). ونظرا لصعوبة ذلك تسعى بعض الجامعات إلى التميز بأحد الأنشطة كجامعة هارفارد مثلاً، استطاعت على مدى سنين عديدة من التميز على الجامعات الأخرى في بعض الأبحاث والدراسات والتخصصات العلمية. بناء استراتيجيه تغيير تزتكز على التطوير النوعي. البحث عن التميز في كل بعد من أبعاد الجامعة الثلاثة أولها نقل المعرفة الذي يتثلل في الجهود المبذولة لتطوير العملية التعليمة، أما الثاني فيتعلق بابداع المعرفة متمثلا بتطوير أساليب البحث العلمي، أما الأخير فهو خدمة البمتمع والمتمثل بتطوير التفاعل مع البيئة الميطة. 


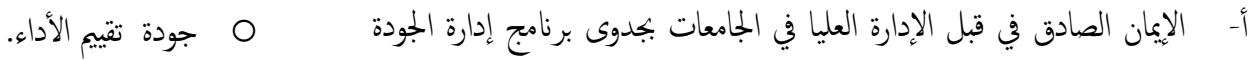

$$
\begin{aligned}
& \text { O جودة القاعات النعلمية وتجهيزاتها }
\end{aligned}
$$

6.1.3 المعوقات والمشكلات التي تؤدي الى ضعف مخرجات التعليم العالي اشارت العديد من الدراسات الى وجود معوقات تواجه تطبيق ادارة الجودة الشاملة

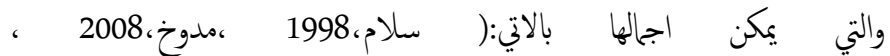
العضاضي، 2012،Diri،2015، النجار و جواد ، 2016).

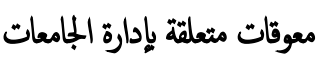
-

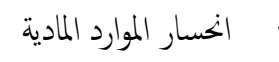

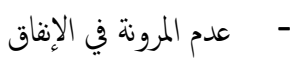

\section{معوقات تتعلق بكفاءة الإدارة الثعلمية}

- عدم الاستقرار على تحديد فلسفة النعليم الجامعي. - - مدم كفاءة نظام القبول في الجامعات. - منية المتحانات وأساليب التقو.م.

معوقات متعلقة بجودة الخدمة التعلمية في الجامعات. - - م الكثافة الطلابية العالية. - عدم التناسب بين أعضاء هيئة التدريس والطلاب. - ازدحام قاعات المحاضرات، المعامل، الورش، المكتبات بالطلاب. - عدم فعالية أدوات العملية التعلمية بالجامعات من حيث النظام الدراسي

$$
\text { والوسائل التعلمية أو المناجج الدراسية. }
$$

- مد عدم الاهتمام بالبحث العلمي بالدرجة الكلفية من حيث التمويل، نقص مساعدي الباحثين، قلة حضور المؤتمرات والندوات العلمية ، نقص

$$
\text { المراجع العلمية المتخصصة ، نقص الأجزة العلمية والمعملية. }
$$

\section{معوقات تتعلق بعدم القدرة على إنتاج خريج وفقاً لمثطلبات حقل العمل} - عدم وجود دراسات معمقة عن احتياجات حقل العمل.
ب- الدع المادي والمعنوي من الإدارة العليا في الجامعات لبرنامج إدارة الجودة الشاملة

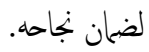

ت- وجود رغبة حقيقية وقناعة تامة من الإدارة العليا في الجامعات في التغيير وتحسين الأداء لأن إدخال برنامج الجودة الشاملة في أي منظمة يعني تغيراً جذرياً في القيم

$$
\text { الإدارية / الحضارة التنظيمية وأساليب العمل. }
$$

ث- عدم التزدد أو عدم إضاعة الوقت في دراسات وأبحاث وأعحال لجان قد تودي إلى قتل فكرة التطبيق في هدها / بل لابد من اخذ زمام المبادرة بالتطبيق المتندج. ج- اختيار قيادة إدارية للبرنامج ذات رؤية مؤثرة ومسلحة بخبرة إدارية وأكاديمية في

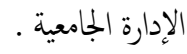

ح- البدء عند تنفيذ برنامج الجودة الشاملة في الجامعات بقطاع الخدمات والإدارة قبل القطاع الأكاديي، لأن الخدمات الإدارية المساندة هي القاسم المشترك الأعظم لعناصر الأداء الإداري الجامعي. خ- تخصيص موارد مالية كافية وبشرية ذات كفاءة عالية لإدارة البرنامج. د- المتابعة الدورية من الإدارة العليا بالجامعات من اجل الوقوف على ما تم انجازه من أهداف وتصحيح الانحرافات عند التنفيذ واتخاذ الخطوات الكنيلة لتثبيت ما تحقق من تحسن وتطور الأداء الجامعي.

5.1.3 المرتكزات الأساسية لتطبيق إدارة الجودة الشاملة في الجامعات أشار (عليمات,2004, 116) إلى المرتكزات الأساسية لتطبيق إدارة الجودة الشاملة في

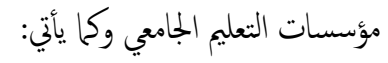

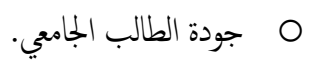
O جودة البرامج التعليمية على مستوى الطلبة. O جودة عضو هيئة الندريس. O جودة طرق الندريس. O جودة الكناب الجامعي. O جودة الإدارة الجامعية. O جودة التمويل. 
عائقا امام تطبيق ادارة الجودة الشاملة , بينا نجد ان (16.2\%) من سبة المبحوثين كان محايدا، اما نسبة غير المثفقين فقد مثلت (11\%) ويدع ذلك الوسط الحسابي وقدره (3.85) والانحراف المعياري (0.969).

من ابرز العناصر التي جاءت بالمرتبة الوولى هو العنصر (X2) الذي ينص على غموض معايير اختيار القيادات الكاديمية وباتفاق (78.8\%) من الافراد المبحوثين ويدع ذلك الوسط الحسابي (3.96) وبانحراف معياري (1.034).كما ان عدم قناعة بعض القيادات الكاديمية بتطبيق ادارة الجودة الشاملة (X1) قد جاء بالمرتبة الاخيرة وبنسبة اتفاق قدره (70.2\%) وبوسط حسابي قدره (3.82)وبانراف معياري (0.909). في هذا السياق لابد من الاشارة التي قام بها (Contle,1990) في جامعة اورجو ن حيث وجد ان نجاح الجامعة في تطبيق ادارة الجودة الشاملة لم تكن عملية سهلة وقد وابحت معوقات لاحصر لها خلال فترة التطبيق , الا أن وجود قيادة فاعلة وكفوءة كانت العامل الاهم في الاستمرار في تطبيق المشروع على وفق رؤية مستقبلية لمستوى الجودة والاداء بالمؤسسة التعلمية التي تقوم على ادارتها وان تعمل على مشاركة كافة المستويات

الادارية داخل المؤسسة التعلمية .

- عدم وجود تفاعل بين الجامعات وحقل العمل. - عدم المشاركة من قبل الفنيين والمهنيين في تصميم البرامج التعليمة. - عدم قدرة الخزيج من الجامعة على الالتحاق بالعمل المناسب

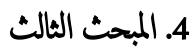

1.4

\subsection{4 وصف وتشخيص عينة البحث}

يتضح من الجدول اعلاه ان نسبة الذكور من المبحوثين هي اكبر بكثير من نبة الاناث حيث بلغت نسبة الذكور 81\% بينا نسبة الاناث 14\%.

وبخصوص اللقب العلمي فقد ظهر ان (51\%) من افراد العينة يحملون لقب مدرس مساعد بينا (37\%) منهم يحملون لقب مدرس اما من يحمل لقب استاذ مساعد ،استاذ من المبحوثين فهو (2\%) و (10\%) على التوالي ـ بالنسبة للفئات العمرية فان الارقام تشير الى ان (56\%) من المبحوثين تتزاوح اعماره بين (40-30) سنة وهذا يدلل على حداثة الندريسيين وهذه النتيجة تتفق مع نسبة الندريسيين الذي يحملون لقب مدرس مساعد حيث بلغ نسبة 51\%.

\section{الجدول رجٌ (1) وصف افراد مجمع المراسة}

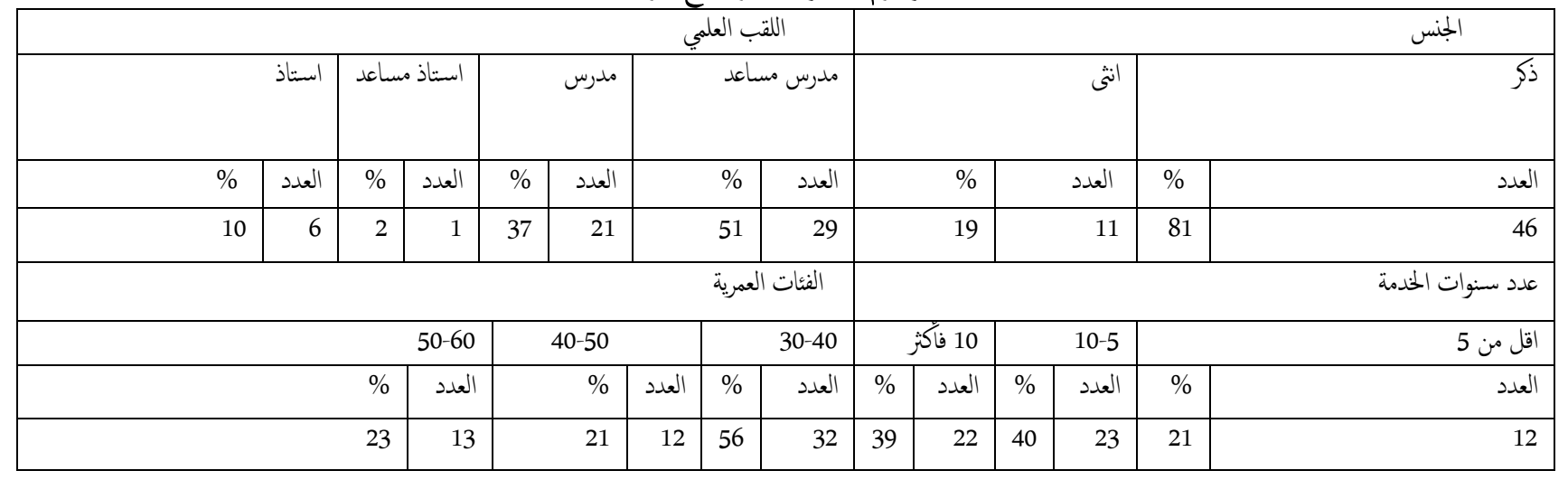

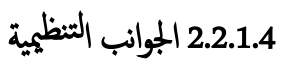

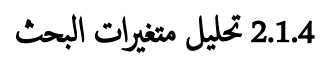

النتائُ الواردة في الجدول (3) تثثل اجابات المبحوثين تجاه الجوانب التنظيمة التي يتم

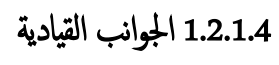
ممارستها من قبل المنظمة البمحوثة باتجاه توفير البنية التنظمية التي تساعد على بناء قاعدة اساسية لنظام ادارة الجودة الشاملة معبرا عنها بالعناصر (X5-X21). تشير معطيات الجدول (2) الى التوزيعات النكرارية وقيم الوسط الحسابي والانحراف المعياري لعناصر المتغير (X1-X4) اذا تشير النسب الم ان (72.8\%) من الافراد المبحوثين متفقون على ان عدم اعطاء الاهمية لعناصر هذا المتغير قد يكون سببا او 
الجدول رج (2) التكرارات والووساط الحساية والانحرافات المعيارية لمثغير الجوانب القيادية

\begin{tabular}{|c|c|c|c|c|c|c|c|c|c|c|c|c|c|}
\hline \multirow{3}{*}{ المعياري } & \multirow{3}{*}{ الحسابي } & \multicolumn{10}{|c|}{ التوزيعات التكرارية المئوية } & \multirow{3}{*}{ العناصر } & \multirow{3}{*}{ المتغير } \\
\hline & & \multicolumn{2}{|c|}{ لا اتفق مطلقا } & \multicolumn{2}{|c|}{ لا لا اتفق } & \multicolumn{2}{|c|}{ محايد } & \multicolumn{2}{|c|}{ اتفق } & \multicolumn{2}{|c|}{ اتفق بدرجة عالية } & & \\
\hline & & $\%$ & ت & $\%$ & ت & $\%$ & ت & $\%$ & ت & $\%$ & ت & & \\
\hline 0.909 & 3.82 & 3.5 & 2 & 1.8 & 1 & 24.5 & 14 & 49.1 & 28 & 21.1 & 12 & $\mathrm{X} 1$ & \multirow{4}{*}{ القيادية } \\
\hline 1.034 & 3.96 & 1.8 & 1 & 12.3 & 7 & 7.0 & 4 & 45.6 & 26 & 33.3 & 19 & $\mathrm{X} 2$ & \\
\hline 1.114 & 3.79 & 5.3 & 3 & 10.5 & 6 & 10.5 & 6 & 47.4 & 27 & 26.3 & 15 & X3 & \\
\hline 0.819 & 3,48 & 3.5 & 2 & 5.3 & 3 & 22.8 & 13 & 43.4 & 25 & 24.6 & 14 & X4 & \\
\hline 0.969 & 3.85 & 3 & & 8 & & 16 & & 47 & & 26 & & & \\
\hline
\end{tabular}

(74\%) من المبحوثين متفقين مع هذا عناصر هذا المتغير في حين نجد ان نسبة الاجابة وبمتوسط حسابي قدره ( 4.5,4.58 )على التوالي .هذه النتيجة تفسر عدم الاهتمام بالحياد وعدم الاتفاق (13\%) لكل منها وقد بلغ متوسط الوسط الحسابي لكافة العناصر العالي على نظم الحوافز المادية والمعنوية .في هذا السياق لابد من الاشارة الى اهية الممثلة لهذا المتغير (3.69) وبانحراف معياري (1.028) وهذه النتيجة تنفق مع دراسة تطبيق الحوافزالمادية والمعنوية في تحفيز اعضاء الهيئة التدريسية والتي هي انعكاس لجودة

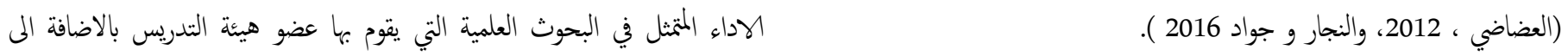
على الرغز من ان جميع المتوسطات الحسابية للعناصر الفرعية لهذا المتغير قد تجاوزت مساهاته الكاديمية الاخرى مثل تأليف الكنب وحضور المؤترات العلمية والمشاركة الوسط الفرضي الذي هو (3) , الا انه يلاحظ وجود اختلاف بنهم من حيث درجة الفعالة في عمليات التحسين المستمر للعمليات الكاديمية ابتداء من اعداد المناجه الموافقة حيث جاء في المرتبة الاولى والثانية ضعف الحوافز المادية والمعنوية (X5,X6) والمقررات واسلوب اكساب المعارف والمهارات للطلاب . الجدول رج(4) النكرارات والاوساط الحسابية والخحرافات المعيارية لمتغير الجوانب التعليمية والمعرفية

\begin{tabular}{|c|c|c|c|c|c|c|c|c|c|c|c|c|c|}
\hline \multirow{3}{*}{ المعياري } & \multirow{3}{*}{ الحسابي } & \multicolumn{10}{|c|}{ التوزيعات التكرارية المئوية } & \multirow{3}{*}{ العناصر } & \multirow{3}{*}{ المتغير } \\
\hline & & \multicolumn{2}{|c|}{ لا اتفق مطلقا } & \multicolumn{2}{|c|}{ لا اتفق } & \multicolumn{2}{|c|}{ محايد } & \multicolumn{2}{|r|}{ اتفت } & \multicolumn{2}{|c|}{ اتفق بدرجة عالية } & & \\
\hline & & $\%$ & ت & $\%$ & ت & $\%$ & ت & $\%$ & ت & $\%$ & ت & & \\
\hline 1.235 & 3.79 & 8.8 & 5 & 8.8 & 5 & 8.8 & 5 & 42.1 & 24 & 31.6 & 18 & X22 & \\
\hline 0.925 & 4.04 & -..- & -- & 7.0 & 4 & 19.3 & 11 & 36.8 & 21 & 36.8 & 21 & X23 & \\
\hline 1.292 & 3.61 & 12.3 & 7 & 1.8 & 1 & 29.8 & 17 & 24.6 & 14 & 31.6 & 18 & X24 & التعلمية \\
\hline 1.187 & 3.81 & 7.0 & 4 & 8.8 & 5 & 12.3 & 7 & 40.4 & 23 & 31.6 & 18 & X25 & المعرفية \\
\hline 1.431 & 3.67 & 14.0 & 8 & 8.8 & 5 & 12.3 & 7 & 26.3 & 15 & 38.6 & 22 & X26 & \\
\hline 1.214 & 3.83 & 9 & & 7 & & 16 & & 34 & & 34 & & & المعدل \\
\hline
\end{tabular}


المراكز البحثية ,قلة مشاركة اعضاء هيئة التدريس في الشراكة مع المراكز البحثية

\subsubsection{4 الجوانب التعلمية والمعرفية}

والعلمية واخيرا غوض المعايير العلمية لتقييم الابحاث فقد كانت اجابات المبحوثين بنفس تون

تشير معطيات الجدول (4) الى التوزيعات النكرارية والنسب المئوية والاوساط الاتجاه الذي أشر على العنصرين (3،13) حيث بلغ معدل الوسط الحسابي (4.18،4.22 الحسابية والانرافات المعيارية لمتغير الجوانب التعلمية والمعرفية اذ بلغت نسبة الاتفاق

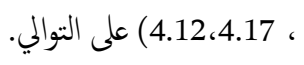

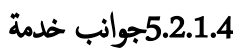

على وقوف هذا المتغير كعقبة امام تطبيق ادارة الجودة الشاملة في المنظمة المبحوثة هو (68\%) ويدع ذلك الوسط الحسابي وقدره (3.85) وبانحراف معياري (1.214) .

المجتع يتضح من الجدول (6) ان هناك اتفاق بدرجة عالية حول عدم تواصل المنظمة المبحوثة مع البجتمع المحلي الذي تعمل فيه حيث اتفق (83\%) من المبحوثين على ان هناك

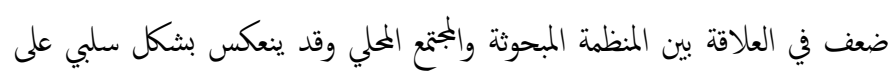
تطبيق ادارة الجودة الشاملة ويدع ذلك معدل الوسط الحسابي والذي قدره (4.21) وبانخراف معياري (0.97) . بينا نجد ان نسبة اجابات المحايدين والغير متفقين (10\%)

$$
\text { (7\%) على التوالي (7\%) }
$$

على الرغ من الاتفاق العام حول عناصر هذا المتغير من قبل المبحوثين الح ان هناك بعض التباين في نسب الموافقة حيث كانت نسبة الاستجابة للعنصر (x35) الذي يعبر

عن ضعف العلاقة بين الجامعة وسوق العمل (86\%) وبوسط حسابي قدره (4.33) وبانحراف معياري (0.912) , اما بالنسبة للاجابة على العنصر (X34) والذي يمثل انعدام معاير قياس رضا العملاء الداخلين والخارجين فقد كانت (68\%) وبوسط حسابي (3.89) وبانخراف معياري (1.046).

من أبرز العناصر التي جاءت في المرتبة الاولى لهذا المتغير هو ضعف ادراك التعلم مدى الحياة (التعليم المستمر ) (X22),حيث بلغ نسبة الاتفاق على هذا العنصر (73.7\%) وبوسط حسابي قدره (4.04) وبانحراف معياري (0.925), بينا حصل العنصر (X23) على نسبة اتفاق (73.6\%) وبوسط حسابي ( 3.79) وبانحراف معياري (1.235)والذي يمثل الهتقاد في ايصال المعرفة على الطرق التقليدية , اما العنصر (X24) والمتمثل بتقييد حرية النعبير والتفكير لدى الطلبة فقد سبل اقل نسبة اتفاق وهي (56.2\%) وبوسط حسابي قدره (3.61) وانحراف معياري (1.292)، في ضوء هذه النتيجة لابد من الاشارة الى ان مدخلات العملية التعليمية من الطلبة في كليات جامعة نوروز وباستثناء كلية الهندسة هم من ذوي المعدلات المنخفضة .

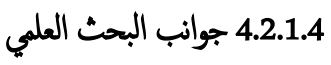

الجدول رة (5) يعرض لنا النتائج التي تم الحصول عليها من خلال اجابات المبحوثين حول العناصر المتعلقة بمتغر جوانب البحث العلمي حيث بلغ نسبة المتفقين حول عناصر هذا المتغير (81\%) بينا بلغت نسبة الاجابة بمحايد (12\%),اما نسبة غير المتفقين حول عناصر هذا المتغير فهو (7\%) وقد بلغ معدل الوسط الحسابي لكافة العناصر الممثلة لهذا المتغير (4.19) وبانحراف معياري (0.901).

هذه النتأُج تفسر لنا عدم اعطاء الاهمية اللازمة لعناصر هذا المتغير والتي قد تكون عقبة في تطبيق ادارة الجودة الشاملة , ويعزز هذا الاستنتاج الاوساط الحسابية لعناصر هذا المتغير حيث الخصرت بين (4.31-4.05) يتقدمم زيادة العبئ التدريسي على حساب البحث العلمي(X27 ) حيث بلغت نسبة الاتفاق حول هذا العنصر (86\%) وبوسط حسابي قدره (4.33 ) وانخراف معياري (0.809) وكذلك ضعف الدئ المادي المقدم للابحاث العلمية حيث بلغ الوسط الحسابي لكل منها (4.31) .اما العناصر المتبقية والتي ركزت على صعوبة تحديد الاحتياجات البحثية رقدة الموارد البشرية المؤهلة في 
الجدول رزٔ(6) انكرارات والاوساط الحسابية والانحرافات المعيارية لمثغير خدمة المجمع

\begin{tabular}{|c|c|c|c|c|c|c|c|c|c|c|c|c|c|}
\hline \multirow{3}{*}{ المعياري } & \multirow{3}{*}{ الحسابي } & \multicolumn{10}{|c|}{ التوزيعات التكرارية المئوية } & \multirow{3}{*}{ العناصر } & \multirow{3}{*}{ المتغير } \\
\hline & & \multicolumn{2}{|c|}{ لا اتفق مطلقا } & \multicolumn{2}{|c|}{ لا اتفق } & \multicolumn{2}{|c|}{ محايد } & \multicolumn{2}{|c|}{ اتفق } & \multicolumn{2}{|c|}{ اتفق بدرجة عالية } & & \\
\hline & & $\%$ & ت & $\%$ & ت & $\%$ & ت & $\%$ & ت & $\%$ & ت & & \\
\hline 1.046 & 3.89 & 3.5 & 2 & 5.3 & 3 & 22.8 & 13 & 35.1 & 20 & 33.3 & 19 & X34 & \\
\hline 0.913 & 4.33 & 1.8 & 1 & 3.5 & 2 & 8.8 & 5 & 31.6 & 18 & 54.4 & 31 & X35 & \\
\hline 0.948 & 4.33 & 1.8 & 1 & 5.3 & 3 & 7.0 & 4 & 31.6 & 18 & 54.4 & 31 & X36 & التعلمية \\
\hline 0.861 & 4.28 & 1.8 & 1 & 3.5 & 2 & 5.3 & 3 & 43.9 & 25 & 45.6 & 26 & X37 & المعرفية \\
\hline 1.086 & 4.23 & 1.8 & 3 & 3.5 & 2 & 7.0 & 4 & 31.6 & 18 & 52.6 & 30 & X38 & \\
\hline 0.97 & 4.2 & 3 & & 4 & & 10 & & 35 & & 48 & & & المعدل \\
\hline
\end{tabular}

تنير النتائُ التي تم الحصول عليها من الجدول (7) بأن هناك اتفاق عالي حول جاء بالمرتبة الاولى العنصر (X42) الذي يمثل التخصيصات المالية التي تضعها المنظمة دورالجوانب المالية في مجال تطبيق ادارة الجودة الشاملة وقد بلغ نسبة الاتفاق حوالي لدع العاملين وكانت نسبة الاتفاق (90\%) وبوسط حسابي قدره (4.33) ويدع ذلك (83\%) وبوسط حسابي قدره (4.15) وانحراف معياري (1.001) فيا يخص نسبة الانحراف المعياري وقدرة (0.893) ـ اما العنصر (X39) فقد جاء بالمرتبة الاخيرة الاستجابة بمحايد فقد بلغت (10\%) بينما نجد ان نسبة عدم الاتفاق قد بلغ (7\%) . والذي يمثل شحة الموارد المالية المتاحة للجامعة وهذا يفسر ان الجامعة لم تخصص الاموال الجدول رمُ(7) التكرارات والاوساط الحسابية ولانحرافات المعيارية لمتغير الجوانب المالية.

\begin{tabular}{|c|c|c|c|c|c|c|c|c|c|c|c|c|c|}
\hline \multirow{3}{*}{ المعياري } & \multirow{3}{*}{ الحسابي } & \multicolumn{10}{|c|}{ التوزيعات التكرارية المئوية } & \multirow{3}{*}{ العناصر } & \multirow{3}{*}{ المتغير } \\
\hline & & \multicolumn{2}{|c|}{ لا اتفق مطلقا } & \multicolumn{2}{|c|}{ لا اتفق } & \multicolumn{2}{|c|}{ محايد } & \multicolumn{2}{|c|}{ اتفق } & \multicolumn{2}{|c|}{ اتفق بدرجة عالية } & & \\
\hline & & $\%$ & ت & $\%$ & ت & $\%$ & ت & $\%$ & ت & $\%$ & ت & & \\
\hline 1.302 & 3.86 & 10.5 & 6 & 5.3 & 3 & 10.5 & 6 & 36.8 & 21 & 36.8 & 21 & X39 & \\
\hline 1.030 & 4.11 & 5.3 & 3 & 1.8 & 1 & 8.8 & 5 & 47.4 & 27 & 35.1 & 20 & X40 & \\
\hline 0.824 & 4.23 & & & 1.8 & 1 & 12.3 & 7 & 47.4 & 27 & 38.6 & 22 & X41 & 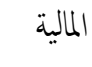 \\
\hline 0.893 & 4.33 & 1.8 & 1 & 3.5 & 2 & 5.3 & 3 & 40.4 & 23 & 49.1 & 27 & $\mathrm{X} 42$ & \\
\hline 0.959 & 4.21 & 3.5 & 2 & 1.8 & 1 & 10.5 & 6 & 38.6 & 22 & 45.6 & 26 & X43 & \\
\hline 1.001 & 4.15 & 4 & & 3 & & 10 & & 42 & & 41 & & & المعدل \\
\hline
\end{tabular}


المعوقات التي تحول دون تطبيق ادارة الجودة الشاملة (84\%) وجاء بوسط حسابي (4.25) وبانحراف معياري (1.09).

8.2.1.4 التحليل الاججالي لمتغيرات معوقات تطبيق ادارة الجودة الشاملة

الجدول رخ (9) يوضح النسب المئوية والمتوسطات الحسابية والاخرافات المعيارية لكافة المتغيرات التي تثثل المعوقات التي تواجه تطبيق ادارة الجودة الشاملة في المنظمة المبحوثة. عند تفحص الارقام الواردة في الجدول نجد بأن اكثر من ثلاثة ارباع المبحوثين (77\% ) أشروا بأن هناك معوقات تحول دون تطبيق ادارة الجودة الشاملة ويدع ذلك معدل

الاوساط الحسابية للمنغيرات وقدره (4.1) وبانحراف معياري قدره (1.017).

على الرغز من أن جميع المتغيرات الواردة في الجدول قد تجاوزت الوسط الفرضي (3) ال ان هناك تبانيا في سبة الاستجابة يتقدهم متغير المالية، خدمة الجمتع، البحث العلمي، اما المتغرات التي تمثل الجانب القيادي والتنظيي فقد اشرت النتائح بأن اكثر من (70\%) من المبحوثين يعتقدون بأن الجانب القيادي والتنظيي له دور في تطبيق ادارة الجودة الشاملة.

الجدول رمّ(8) التوزيعات التكرارية والوساط الحساية والاخرافات المعيارية لمتغير الجوانب الطلايية.

\begin{tabular}{|c|c|c|c|c|c|c|c|c|c|c|c|c|c|}
\hline \multirow{3}{*}{ المعياري } & \multirow{3}{*}{ الحسابي } & \multicolumn{10}{|c|}{ التوزيعات التكرارية المئوية } & \multirow{3}{*}{ العناصر } & \multirow{3}{*}{ المتغير } \\
\hline & & \multicolumn{2}{|c|}{ لا اتفق مطلقا } & \multicolumn{2}{|c|}{ لا لا تفق } & \multicolumn{2}{|c|}{ محايد } & \multicolumn{2}{|c|}{ اتفق } & \multicolumn{2}{|c|}{ اتفق بدرجة عالية } & & \\
\hline & & $\%$ & ت & $\%$ & ت & $\%$ & ت & $\%$ & ت & $\%$ & $ت$ & & \\
\hline 1.222 & 3.84 & 5.3 & 3 & 7.0 & 4 & 22.8 & 13 & 26.3 & 15 & 38.6 & 22 & X44 & \\
\hline 1.465 & 3.18 & 19.3 & 11 & 15.8 & 9 & 17.5 & 10 & 22.8 & 13 & 24.6 & 14 & X45 & \\
\hline 0.990 & 4.14 & 3.5 & 2 & 3.5 & 2 & 10.5 & 6 & 40.4 & 23 & 42.1 & 24 & X46 & ل لطلابية \\
\hline 1.090 & 4.25 & 3.5 & 2 & 3.5 & 2 & 7.0 & 4 & 29.8 & 17 & 54.4 & 31 & X47 & \\
\hline 0.954 & 4.31 & 3.5 & 2 & 1.8 & 1 & 7.0 & 4 & 31.6 & 18 & 56.1 & 32 & X48 & \\
\hline 1.144 & 3.94 & 7 & & 7 & & 13 & & 30 & & 43 & & & لمعدل \\
\hline
\end{tabular}

\subsubsection{4 الجوانب الطلابية}

الجدول رقز (8) يعرض لنا الننائُ التي تم الحصول عليها والتي تثثل اجابات المبحوثين حول متغير الجوانب الطلابية ـ (73\%) من المبحوثين متفقين على ان العناصر المكونة لهاذا المتغبر لها دور واضح في تطبيق ادارة الجودة الشاملة ويدع ذلك الوسط الحسابي (3.99) بانخراف معياري (1.14) (- ) من ابرز العناصر التي جاءت بالمرتبة الاولى هو العنصر (X48) الذي ينص على ضعف ادراك الطلبة لمفهوم الجودة مسؤولية الجميع وباتفاق (74\%) من اراء المبحوثين ويدع ذلك الوسط الحسابي قدره (4.31) وبانحراف معياري (0.954). اما العنصر (X47) فقد جاء بالمرتبة الثانية ومتقاربا مع العنصر (X48) والني ينص على غياب دافعية الطلبة للتعليم اذ بلغت نسبة الموافقة على اعتبارهذا العنصر هواحد 
2.5

نشر ثقافة الجودة بين العاملين من خلال اقامة الدورات التثقيفية التي على مفهوم الجودة في التعلييم ومتطلبات تطبيق ادارة الجودة الشاملة. اعادة النظر في الهياكل التنظيمة وبما يتلائم مع الاهداف المطلوبة للمرحلة الجديدة. اختيار القيادات الكاديمية من ذوي الكفاءة والاختصاص زيادة التخصيصات المالية لتفعيل البحث العلمي والتاليف والتزبمة والمؤمرات العلمية الداخلية والخارجية. التركيز على تعيين الكوادر التدريسية من ذوي الالقاب العلمية العالية (استاذ

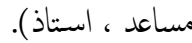
تفعيل العلاقة بين الجامعة والمجتع المحلي من خلال المشاركة المتبادلة في الانشطة

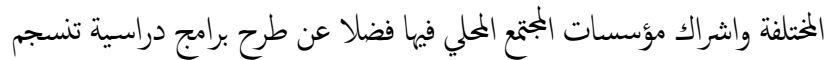
مع حاجات السوق المحلية للتغلب على مشكلة البطالة. اعتاد نظام حوافز لتشجيع الندريسيين والموظفين للارتقاء بادائه الكادييي والوظيفي. دع واسناد وحدات الجودة في الجامعة والكليات التابعة لها ليتسنى لها متابعة

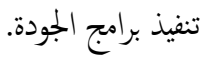

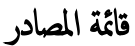

أبو عودة, فوزي، ( 2000), مؤشرات الجودة في التعليم العالي, المؤمر التربوي الأول, التربية في فلسطين ومتغيرات العصر, كلية التربية, الجامعة الإسلامية, غزة.

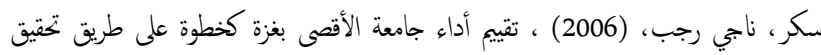

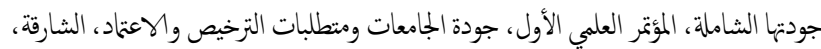
الإمارات العربية المتحدة.

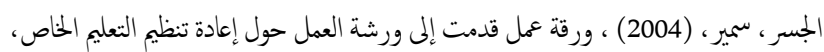

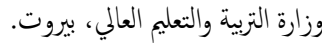

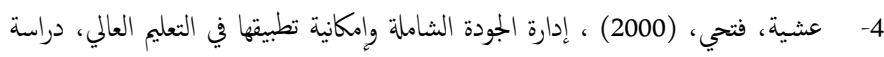

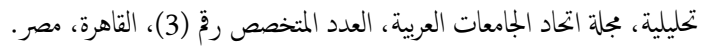

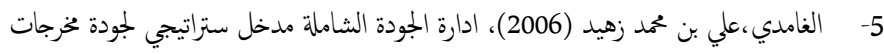

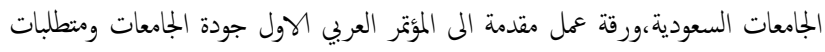
التزخيص والاعتماد. الشبتري، الحسن بن علي سعيد، (2000) ، مبادئ إدارة الجودة الشاملة لـ (Deming) بين الاعنات

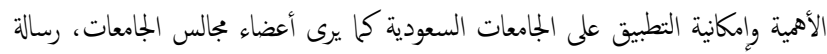
دكتوراه غير منشورة، مكة المكرمة. 7- العلوي, حسين محمد علي، (1998), إدارة الجودة الشاملة في مؤسسات التعليم العالي, مركز

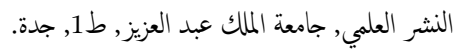
عليات، صاح ناصر، (2004) ، إدارة الجودة الشاملة في المؤسسات التربوية (التطبيق

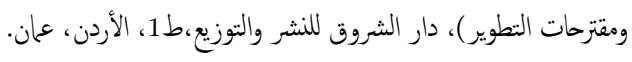

الجدول رم (9) الاوساط الحسايية والاخرافات المعيارية لمعوقات تطبيق ادارة الجودة الشاملة.

\begin{tabular}{|c|c|c|c|}
\hline $\begin{aligned} \text { المحرافارية } \\
\text { المعيات }\end{aligned}$ & المتوسطات & نالسبة & المتغيرات \\
\hline 0.906 & 3.85 & 73 & القيادية \\
\hline 1.028 & 3.96 & 74 & التنظيمية \\
\hline 1.214 & 3.83 & 68 & التعليمية والمعرفية \\
\hline 0.901 & 4.20 & 82 & البحث العلمي \\
\hline 0.970 & 4.20 & 83 & خدمة المجتمع \\
\hline 1.001 & 4.15 & 83 & المالية \\
\hline 1.100 & 3.94 & 73 & الطلابية \\
\hline 1.017 & 4.01 & 77 & المعدل \\
\hline
\end{tabular}

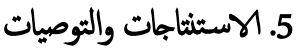

افرزت الدراسة الحالية مجموعة من الاستنتاجات والتي في ضوئا تم تقديم عددا من

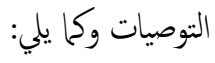

1 1.5 الاستناجات

1عدم وجود وعي كافي لدى المبحوثين في المنظمة المبحوثة باهمية وفوائد ادارة

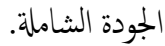
2- ضعف كفاءة بعض القيادات الككاديمة.

3- عدم فاعلية الهياكل التنظيمية على مستوى الجامعة والكليات التابعة لها.

4-ضعف الاهتمام بالبحث العلمي من قبل التدريسيين واقتصاره لاغراض الترقية

العلمية فتط. 5- ضعف الحوافز المادية والمعنوية الممنوحة للعاملين. 6- زيادة العبئ الثدريسي على حساب البحث العلمي وتطوير المناجج الدراسية. 7- قلة الكوادر الندريسية من ذوي الالقاب العلمية العالية (استاذ مساعد،

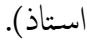
8- ضعف العلاقة بين الجامعة والمجتع المحلي. 
المجلة الأكاديمية لجامعة نوروز

$$
\begin{aligned}
& \text { 9- مدوخ، (2008)، نصر الدين حمدي سعيد، معوقات تطبيق ادارة الجودة الشاملة في الجامعات }
\end{aligned}
$$

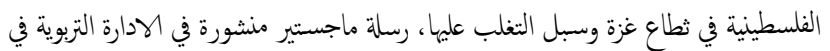

$$
\begin{aligned}
& \text { كلية التربية بالحامعة الهسلامية، غزة. } \\
& \text { 10- العضاضي، سعيد بن علي (2012)، معوقات تطبيق ادارة الجودة الشاملة في مؤسسات التعليم }
\end{aligned}
$$

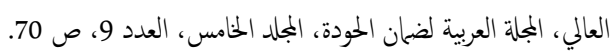

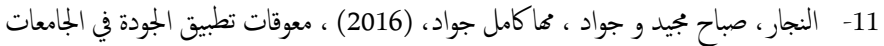

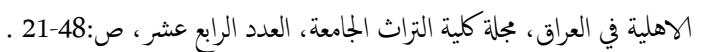

12- Diri, Z, (2015), Identifying the Obstacles to the Application of (TQM)

In the Business Management Departments In Jordanian Private Universities, International Journal of Management Sciences, Vol.5, N, 5. Pp 305-314. 